\title{
Effects of heat and cyclic reuse on the properties of bentonite-bonded sand
}

\author{
Korbinian SCHIEBEL ${ }^{1}$, Guntram JORDAN ${ }^{1, *}$, Anders KAESTNER $^{2}$, BurkHard SCHILLINGER ${ }^{3}$, \\ Robert GEORGII ${ }^{3}$, KaI-Uwe HESS ${ }^{1}$, SANDra BÖHNKE ${ }^{4}$ and Wolfgang W. SCHMAHL ${ }^{1}$ \\ ${ }^{1}$ Ludwig-Maximilians-Universität München, Department für Geo- und Umweltwissenschaften, Theresienstr. 41, \\ 80333 München, Germany \\ *Corresponding author, e-mail: guntram.jordan@1rz.uni-muenchen.de \\ ${ }^{2}$ Paul Scherrer Institute, 5232 Villigen-PSI, Switzerland \\ ${ }^{3}$ Heinz Maier-Leibnitz Zentrum (MLZ) and Physik Department, Technische Universität München, \\ Lichtenbergstr. 1, 85748 Garching, Germany \\ ${ }^{4}$ Imerys Metalcasting Germany GmbH, Schmielenfeldstr. 78, 45772 Marl, Germany
}

\begin{abstract}
Bentonite-bonded quartz sand is the most common mould material used in foundry industry. During casting, however, the moulding sand undergoes alterations, which deteriorate its properties. Aim of this work, therefore, was to gain accurate insights into the relation between smectite alteration and property change. To this end, the wet tensile strengths of heat pre-treated and cyclically reused sands were related to the kinematics of water within the sand as measured by in-situ neutron radiography and neutron diffraction. Sands subjected to 22 cycles of drying $\left(T=120^{\circ} \mathrm{C}\right)$ and remoistening $(3 \mathrm{wt} \%)$ revealed modifications of the $d$ values of the basal reflections of smectites. No significant change of tensile strength, however, was associated with these modifications. Contrarily, sands pre-treated with temperatures as low as $225^{\circ} \mathrm{C}$ revealed a reduction of tensile strength, which was neither correlated to the loss of tightly bound water nor to dehydroxylation. For temperatures above $300{ }^{\circ} \mathrm{C}$ a correlation between the reduction of tensile strength and the loss of tightly bound water or early dehydroxylation was evident. With completing dehydroxylation of the smectites above $670{ }^{\circ} \mathrm{C}$, total loss of wet tensile strength of the pre-heated sands was observed. The results showed that cyclic use of moulding sand had little impact on the sand quality as long as the temperature of the sand remained low. For the practice in foundry, the results imply that a rigorous separation of heat-exposed sand is advantageous.
\end{abstract}

Key-words: Bentonite; smectite; neutron radiography; neutron diffraction; metal casting; moulding sand; foundry; tensile strength; recycling.

\section{Introduction}

Bentonite with a smectite content of more than $70 \%$ is the most commonly used binder for quartz sand utilised as mould material in foundry industries (Grefhorst, 2006). Because of lower particulate and organic emission during casting, bentonite-bonded sands have an excellent environmental performance compared to organically bonded sands (Wang et al., 2007a and b). Furthermore, bentonite-bonded sands can be reused for mould production many times (Zabat \& Van Damme, 2000). Sands discarded after a maximum of cycles can then be used as raw material for concrete (Fiore \& Zanetti, 2007; Siddique et al., 2009; Guney et al., 2010), ceramics (Raupp-Pereira et al., 2006; Alonso-Santurde et al., 2012), or as hydraulic barrier for landfills (Zanetti \& Godio, 2006).

The amount of bentonite binder in fresh unused moulding sands (so called green sands) typically is $5-10 \mathrm{wt} \%$ (Tilch et al., 2002). Depending on the bentonite content, green sands contain 3-5 wt $\%$ water as well as optional additives. During casting, temperature and local moisture content changes within the mould. When the metal melt enters the mould, sand next to the mould cavity heats up and dehydrates. The emerging steam diffuses into colder regions where it condensates. As the heat advances, evaporation and condensation proceed forward (Kubo \& Pehlke, 1986). The changes in temperature and moisture lead to modifications of bentonite properties, which are irreversible in parts. A reduced stability and reusability of the mould material is the consequence (Patterson \& Boenisch, 1961, 1964). Furthermore in the contact region between metal melt and moulding sand, smectites are exposed to temperatures above the dehydroxylation temperature changing the sand properties permanent and irreversible.

At temperatures below $100{ }^{\circ} \mathrm{C}$, montmorillonite loses parts of the interlayer water in a step-wise manner (Ferrage et al., 2007; Schnetzer et al., 2016). While this process is assumed to be reversible, the influences of steam and temperatures above the boiling point of water on the behaviour of smectites remain ambiguously (Mooney et al., 1952a and b; Keren \& Shainberg, 1975, 1979; Couture, 1985; Oscarson \& Dixon, 1989; Case et al., 1992; Beren et al., 
1995). In contrast to the findings of Couture (1985) and Oscarson \& Dixon (1989), Heuser et al. (2014) measured significant changes in cation exchange capacity only in the case of monovalent interlayer cations and, additionally, detected no effects on the structure of the mineral. Furthermore, no significant changes of hydraulic and mechanical properties have been reported for bentonite materials exposed to temperatures of $120{ }^{\circ} \mathrm{C}$ under wet conditions (Wersin et al., 2007). At temperatures higher than $220^{\circ} \mathrm{C}$, reports are unequivocal. At $500-800{ }^{\circ} \mathrm{C}$, intra-layer hydroxyl groups are removed (Emmerich et al., 1999) and the montmorillonite structure disintegrates irreversibly.

Although the general heat-induced effects on the montmorillonite structure have been examined intensively, the effects of heat on moisture transport and, therefore, on the binding properties of bentonite-bonded moulding sands were subject to only very few studies (Holtzer et al., 2011; Bobrowski \& Grabowska, 2012; Zymankowska-Kumon et al., 2012). Likewise, effects of cyclic reuse on the properties of moulding sand are far from being known satisfactorily. Altered water transport within the sand during casting often is correlated with decreased wet tensile strength, which substantially degrades the quality of moulding sand. In order to study both mechanical strength and water transport properties, wet tensile testing (Schiebel et al., 2018), neutron radiography (Schillinger et al., 2011; Hall, 2013; SedighiGilan et al., 2013), and neutron diffraction were applied here. The simultaneous application of wet tensile testing and neutron radiography, in particular, allowed for a correlation of tensile strength with both the position of the rupture plane and the local water content of the sand with a spatial resolution in the sub-mm range and a sub-second temporal resolution (Schiebel et al., 2018). Neutron diffraction gave information about water residing within the smectite interlayers at given time and temperature. Altogether, the experiments allowed a detailed evaluation of the sand properties induced by heat and cyclic reuse. The aim of this work, therefore, was to gain deeper insights into the changes of the properties of moulding sand induced by heat or its continuous reuse.

\section{Materials and method}

\subsection{Materials}

Bentonite-bonded sand consisting of $92 \mathrm{wt} \%$ quartz (average grain size approx. $0.3 \mathrm{~mm}$ ) and $8 \mathrm{wt} \%$ natural bentonite (Wyoming) was obtained from S\&B Minerals (Imerys, Marl, Germany). Analysis of comparable bentonite from the same source yielded approx. $87 \mathrm{wt} \%$ smectite and $13 \mathrm{wt} \%$ of other minerals (mainly feldspar, quartz, and calcite; Jordan et al., 2013).

Two suites of experiments were performed. For the first suite of experiments, aliquots of approx. $1 \mathrm{~kg}$ of the sand were dried at $120{ }^{\circ} \mathrm{C}$ for $24 \mathrm{~h}$ in a drying chamber. While continuously mingling with an electric blender, the aliquots were remoistened to $3 \mathrm{wt} \% \mathrm{H}_{2} \mathrm{O}$ by slowly adding approx.
$30 \mathrm{~mL}$ water. After a further mixing for $10 \mathrm{~min}$, the remoistened sand was finally aged for $24 \mathrm{~h}$ in an airtight bag. In total, this drying, remoistening, blending and ageing procedure was cyclically repeated 13,22 or 25 times (the latter was used for propagation constant measurements only). The exact amount of water added in each cycle was referred to the dry weight measured directly before remoistening. For the second suite of experiments, aliquots of approx. $1 \mathrm{~kg}$ of moulding sand containing $3 \mathrm{wt} \% \mathrm{H}_{2} \mathrm{O}$ were heat-treated for $24 \mathrm{~h}$ in a muffle furnace at $T=225,330$, $390,435,540,645$, or $750{ }^{\circ} \mathrm{C}$, remoistened $\left(3 \mathrm{wt} \% \mathrm{H}_{2} \mathrm{O}\right)$, blended for $10 \mathrm{~min}$ and aged in airtight bags for at least $24 \mathrm{~h}$. As reference in both experimental suites, fresh and unused sand was dried once at $120{ }^{\circ} \mathrm{C}$ for $24 \mathrm{~h}$ in a drying chamber, remoistened to $3 \mathrm{wt} \% \mathrm{H}_{2} \mathrm{O}$, blended for $10 \mathrm{~min}$ and aged in airtight bags for at least $24 \mathrm{~h}$. This single drying-remoistening procedure was essential in order to obtain sand with a defined amount of water.

\subsection{DSC and TG}

The dried and un-remoistened reference moulding sand was simultaneously examined by differential scanning calorimetry (DSC) and thermogravimetry (TG) in order to determine dehydroxylation temperatures of the smectite within the moulding sand precisely. These DSC and TG data could be correlated with the temperatures of the dehydration and dehydroxylation of the moulding sand observed by neutron radiography and neutron diffraction. For the thermal analysis (Thermo Microbalance STA 449 F1; Netzsch), 63.05 mg of the sand was heated in a static argon atmosphere in a Pt-crucible $(256.74 \mathrm{mg})$, which was closed with a lid with a small hole. As reference, an empty crucible of the same shape and weight was used. The heating rate was $10 \mathrm{~K} / \mathrm{min}$. The final temperature was $1000{ }^{\circ} \mathrm{C}$. A temperature calibration has been performed by using the extrapolated onset of the melting points of indium and zinc. The uncertainty of the temperature measurement is smaller than $1 \mathrm{~K}$.

\subsection{Neutron radiography time series of heated tensile testing}

For the tensile tests, a two part aluminium tube was used (Fig. 1). The lower prismatic part had a quadratic cross section $(44 \mathrm{~mm} \times 44 \mathrm{~mm})$ and a height of $100 \mathrm{~mm}$. The quadratic cross section of the upper pyramidal part (height $20 \mathrm{~mm}$ ) increased from $44 \mathrm{~mm} \times 44 \mathrm{~mm}$ to $54 \mathrm{~mm} \times$ $54 \mathrm{~mm}$. The two-part specimen tube was turned upside down and filled with sieved sand. Subsequently, the sand within the tube was compressed with $1 \mathrm{MPa}$, yielding a porosity of $48 \pm 3 \mathrm{vol} \%$. To simulate the casting conditions, a temperature and moisture gradient was induced by heating the sample from above with a heating plate $\left(T=310^{\circ} \mathrm{C}\right)$. The temperature within the sand sample was monitored with type $\mathrm{J}$ thermocouples at four different distances to the heating plate. After defined heating periods (120 or $180 \mathrm{~s}$ ), tensile tests were performed (loading ramp $50 \mathrm{~N} / \mathrm{s}$ ). 


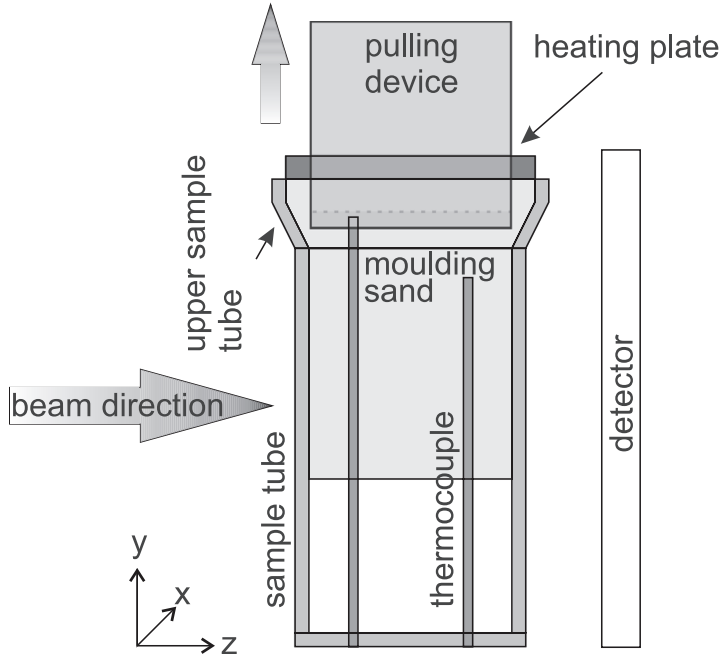

Fig. 1. Sketch of the wet tensile testing set up and its orientation in the neutron beam.

These heating periods yielded flat rupture planes at the intended position within the sample tube. In order to quantify the binding properties of the differently treated sands, at least five wet tensile tests were performed. At least two of these tests were imaged by neutron radiography which revealed the water kinematics during the entire heating and tensile testing period. The neutron radiography time series were performed at ICON (SINQ, Paul Scherrer Institute, Switzerland; Kaestner et al., 2011) and ANTARES (FRM II, Heinz Maier-Leibnitz Zentrum, Germany; Schulz \& Schillinger, 2015). At ICON, samples with cyclically dried and remoistened sands were investigated using a CMOS camera (4 frames $/ \mathrm{s}$, spatial resolution $=0.05 \mathrm{~mm} / \mathrm{pixel})$. At ANTARES, tensile tests of heat pre-treated sands were conducted using a CCD camera $(0.55$ frames/s, $2 \times 2$ binning, spatial resolution $=0.15 \mathrm{~mm} /$ pixel). Tensile strength $\sigma_{\mathrm{t}}$ was calculated according to Eq. (1), where $F_{\mathrm{r}}$ is the measured maximum tensile force, $F_{\mathrm{g}}$ is the weight of the upper sample part (Fig. 1), and $A$ is the cross sectional area at the specimen neck.

$\sigma_{t}=\frac{F_{\mathrm{r}}-F_{\mathrm{g}}}{A}$.

Water kinematics was quantified from neutron radiographs. The radiographs were corrected for white and dark spots, background noise, and beam fluctuations according to Hassanein et al. (2006). The local water content was calculated from corrected radiographs according to the procedure explained in detail by (Schiebel et al., 2018). In short, the water content $w$ at the pixel position $x, y$ and time $t$ is:

$w(x, y, t)=\frac{\left(\ln \left(\frac{\tau_{\mathrm{s}}^{\mathrm{cor}}}{g(y)}\right)-\ln \left(\frac{\tau(x, y, t)^{\mathrm{cor}}}{g(y)}\right)\right)}{\Theta_{\mathrm{W}}}$,

where $\tau^{\text {cor }}$ is the corrected neutron transmission measured at each pixel $(x, y)$ in the radiograph taken at time $t ; \tau_{\mathrm{s}}^{\text {cor }}$ is the corrected neutron transmission of the dry sand; $\Theta_{\mathrm{W}}$ is the correlation factor between water content and neutron transmission calculated from calibration measurements (Schiebel et al., 2018); $g(y)$ is the sample geometry normalisation factor, which takes account for the specific geometry of the two-part specimen tube.

Using Eq. (2), the local water content could be assigned to all sample positions within the radiographs (Fig. 2). From each radiograph, a vertical profile of water content was taken along the centre of the sample tube. In these profiles, the positions of the boundaries between the dry zone, evaporation zone, condensation zone, and external zone were determined. The boundary between evaporation zone and condensation zone was assigned to the moisture maximum. Allocation of the boundaries between dry zone and evaporation zone as well as between condensation zone and external zone was not trivial. At both boundaries, the water content of one zone continuously approached the water content of the neighbouring zone. The boundary between condensation zone and external zone, therefore, was allocated to the position where the local moisture exceeded the initial water by more than $1 \%$. The position of the boundary between the dry zone and the evaporation zone was assigned to the location where the moisture content is less than $0.03 \mathrm{wt} \% \mathrm{H}_{2} \mathrm{O}$.

Heat driven water kinematics within the sample tube could be characterized by the propagation constants $q$ of the zone boundaries. According to Kubo \& Pehlke (1986), these propagation constants could be approximated by:

$q=\frac{\Delta y}{\sqrt{t}}$

where $\Delta y$ are the positions of the respective zone boundaries in the radiographs taken at time $t$. The propagation constants presented here were computed by linear regressions of data in plots of $\Delta y$ versus $\sqrt{t}$.

\subsection{Neutron diffraction}

At the neutron diffraction beam line MIRA (FRM II, Heinz Maier-Leibnitz Zentrum, Germany; Georgii \& Seemann, 2015; Georgii et al., 2018), both heat pre-treated and cyclically reused sands were investigated at defined conditions in order to estimate the amount of water located within the smectite interlayers. Compared to X-ray, neutrons strongly interact with water, leading to higher intensities of the smectite reflections in moist condition. With decreasing water content, the intensities also decrease.

For the experiments, the moist sand $\left(3 \mathrm{wt} \% \mathrm{H}_{2} \mathrm{O}\right)$ was filled into an aluminium vial (ø18 mm, height $50 \mathrm{~mm}$ ) and compressed with $1 \mathrm{MPa}$. Immediately after compaction, a lid was screwed on the vial. The lid had a hole $(\varnothing 3 \mathrm{~mm})$ for pressure release by venting air and water vapour. Through the hole, a thermocouple $(\varnothing 2 \mathrm{~mm})$ was fed into the vial. The thermocouple tip was positioned in the centre of the sample. The semi-open vial design closely matched the conditions within the moulding sand during casting, where ambient pressure was fairly maintained in the open pore system by transport 

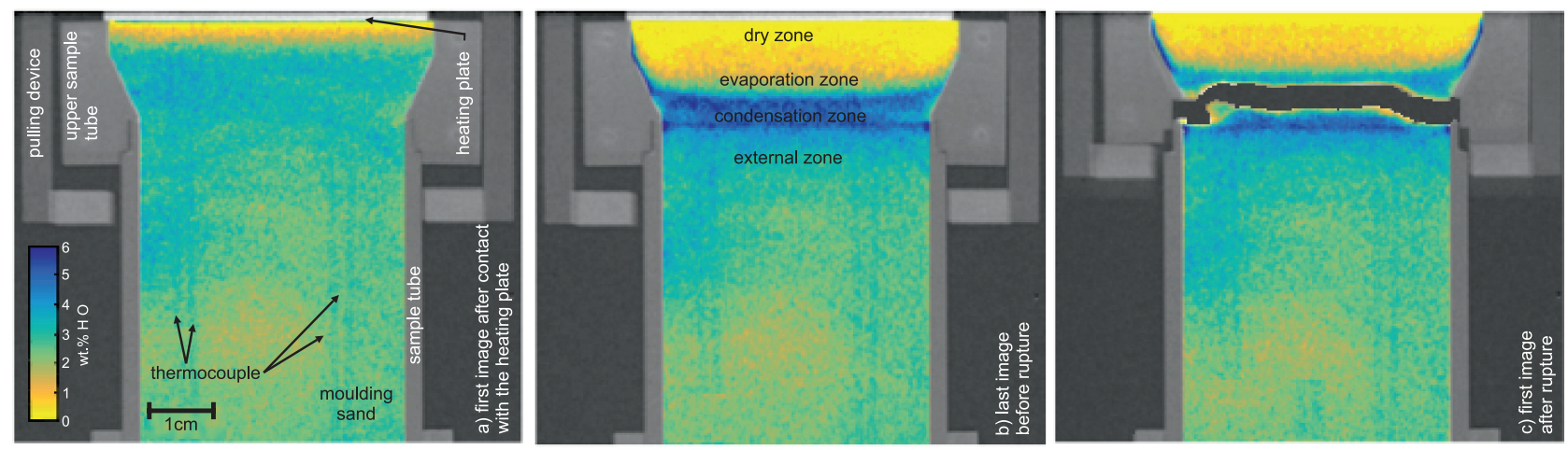

Fig. 2. Neutron radiographs of wet tensile testing of the reference sand. (a) First radiograph taken after contact of the heater. The moisture of the sand is colour coded. (b) Last radiograph taken before rupture. Dry zone, evaporation zone, condensation zone, and external zone are labelled. (c) First radiograph taken after rupture.

of air and water vapour away from the hot mould cavity towards the neighbouring colder areas.

The vial with the moist sand was heated with a furnace mounted on the instrument thus allowing for in situ neutron diffraction from room temperature to $135{ }^{\circ} \mathrm{C}$ in steps of 5 or $10 \mathrm{~K}$. At each step, the temperature was held for 40 or $60 \mathrm{~min}$ to evaluate the swelling state of smectites. During both heating and holding, diffraction patterns were continuously taken at $5-35^{\circ} 2 \theta$ with a step width of $0.4^{\circ} 2 \theta$ and an exposure time of $2 \mathrm{~s}$. Before heating and at the end of each experiment, diffraction patterns were taken from $5^{\circ}$ to $120^{\circ} 2 \theta$. By the positions of the quartz peaks (determined by basic Gaussian fitting after background subtraction), the wavelength $(4.502 \pm 0.009 \AA)$ was continuously monitored. The quartz reflection data used for the calculation were taken from Ogata et al. (1987) $\left(d_{100}=4.2277 \AA, \quad d_{101}=\right.$ $d_{011}=3.3230 \AA$ ). From each diffraction pattern, the average $d_{001}$ value of the smectite was calculated by fitting the peak with a single Gaussian function after a background subtraction and an integration of the previous and subsequent scan.

\subsection{SEM}

Scanning electron microscopy (SEM) images were taken from sand flakes coated with a carbon layer $(\approx 10 \mathrm{~nm})$. The sand flakes were made from moist sand $\left(3 \mathrm{wt} \% \mathrm{H}_{2} \mathrm{O}\right)$ by compression with $1 \mathrm{MPa}$ and vacuum drying of the pressed flakes at room temperature. Images were taken with a Hitachi SU5000 microscope equipped with a field emission gun. Semi-quantitative chemical analyses by energydispersive spectroscopy (EDX, AzTec, Oxford Instruments) were performed using an accelerating voltage of $20 \mathrm{kV}$ and a working distance of $10 \mathrm{~mm}$.

\section{Results}

\subsection{Thermal analysis of the moulding sand}

Between room temperature and $200{ }^{\circ} \mathrm{C}$, TG showed a weight loss of only $0.06 \mathrm{wt} \%$, which can be regarded as meaningless. From $200{ }^{\circ} \mathrm{C}$ to $670{ }^{\circ} \mathrm{C}$, a continuous mass

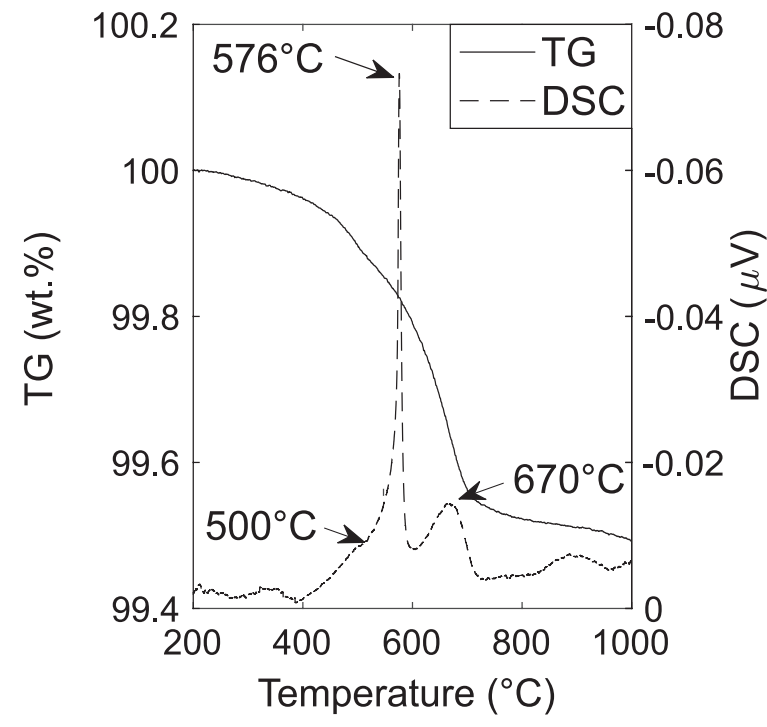

Fig. 3. DSC and TG curves (heating rate $10 \mathrm{~K} / \mathrm{min}$ ) of a moulding sand with a bentonite content of $8 \mathrm{wt} \%$. For the analysis, the reference sand was used, which previously was subject to drying at $120{ }^{\circ} \mathrm{C}$. The $\alpha$-quartz transformation starts at $573{ }^{\circ} \mathrm{C}$ and reaches maximum transformation rate at $576{ }^{\circ} \mathrm{C}$.

loss of $0.43 \mathrm{wt} \%$ occurred (Fig. 3). At $500{ }^{\circ} \mathrm{C}$, a significant change of the mass loss rate took place. At $725^{\circ} \mathrm{C}$, the mass loss rate decreased to almost zero. Therefore, the weight loss from 725 to $1000{ }^{\circ} \mathrm{C}$ was smaller than $0.05 \mathrm{wt} \%$.

DSC (Fig. 3) showed an endothermic peak beginning at $400{ }^{\circ} \mathrm{C}$ with a maximum at $500{ }^{\circ} \mathrm{C}$, correlating with the observed change in mass loss rate by TG. The peak at $500{ }^{\circ} \mathrm{C}$ overlapped with a large endothermic peak at $576{ }^{\circ} \mathrm{C}$. A third peak with a maximum at $670{ }^{\circ} \mathrm{C}$ (ending at $720^{\circ} \mathrm{C}$ ) correlated with a strong mass loss in TG. Further extensively overlapping endothermic peaks could be observed at temperatures above $800{ }^{\circ} \mathrm{C}$.

\subsection{Wet tensile strength of heat pre-treated and cyclically reused sands}

In the reference sand, rupture occurred at the boundary between evaporation and condensation zone (Fig. 2c). This 


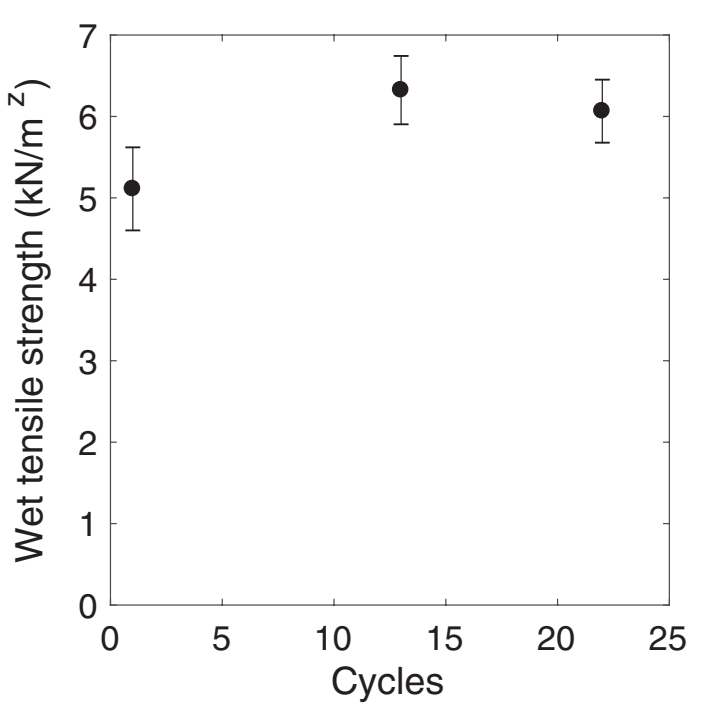

Fig. 4. Wet tensile strengths of moulding sands ( $3 \mathrm{wt} \%$ water) subjected to 1,13 , and 22 drying-remoistening cycles. Drying temperature was $120^{\circ} \mathrm{C}$ for $24 \mathrm{~h}$ in a drying chamber.

boundary coincided with the $100{ }^{\circ} \mathrm{C}$ isotherm (Schiebel et al., 2018). The experiments with cyclically reused sands showed that the coincidence of the rupture position with this boundary was not significantly affected by the number of cycles. Likewise, the tensile strengths of cyclically reused sands revealed no significant dependence on the number of cycles (Fig. 4) and remained close to the value of $5.2 \pm 0.5 \mathrm{kN} / \mathrm{m}^{2}$ which had been obtained for the reference sand.

The tensile strengths of heat pre-treated sands, however, were generally lower than the strength of the reference sand (Fig. 5). Sand pre-treated at $225^{\circ} \mathrm{C}$ revealed a tensile strength of $3.8 \pm 0.4 \mathrm{kN} / \mathrm{m}^{2}$. Pre-treatment at $540{ }^{\circ} \mathrm{C}$ yielded a value of $3.1 \pm 0.4 \mathrm{kN} / \mathrm{m}^{2}$. For sands pre-treated at temperatures of $645{ }^{\circ} \mathrm{C}$ and higher, tensile strengths were below detection limit. The sand in the dry zone of these samples just fell apart and disintegrated into grains upon pulling the upper part of the sample tube. This behaviour was different to all other sands examined here, which had significant tensile strengths in the dry zone.

\subsection{Water kinematics in the sand column}

Evaporation of water in the sand started instantaneously when contact to the heating plate had been established. The generated steam diffused into the lower parts of the specimen and condensed. At a given position within the sand column, therefore, the local moisture first increased and then decreased as the dry zone advanced further. This water transport behaviour was present in all samples examined here (Fig. 6). A more detailed evaluation of the transport by a quantitative comparison of the propagation constants of the zone boundaries, however, revealed some differences among the different sands (Figs. 7, 8).

The propagation constants of the reference sand were $0.15 \pm 0.01 \mathrm{~mm} / \sqrt{(s)}, \quad 0.85 \pm 0.02 \mathrm{~mm} / \sqrt{(s)}, \quad$ and

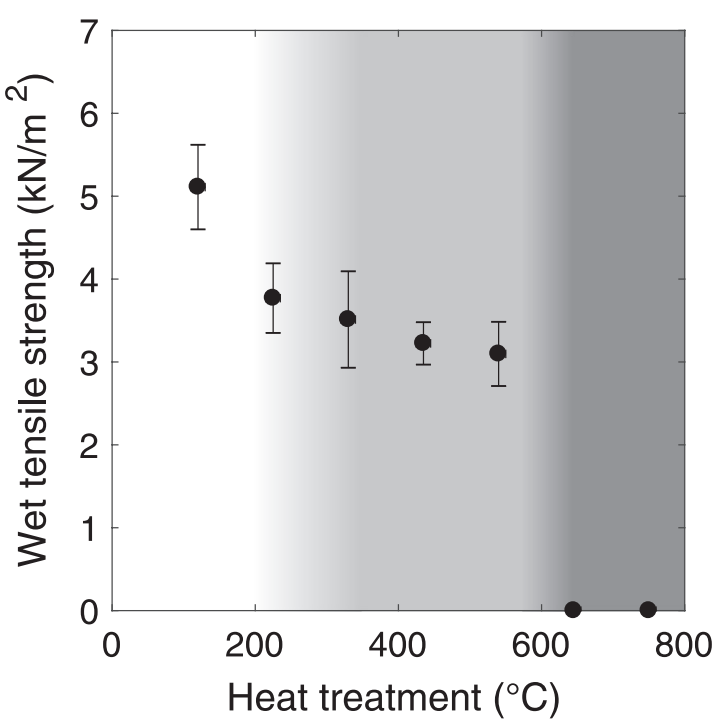

Fig. 5. Wet tensile strengths of moulding sands pre-treated at different temperatures. Different degrees of weight loss during heat pre-treatment as detected by thermal analyses (Fig. 3) were indicated by different greyscales.

$2.80 \pm 0.15 \mathrm{~mm} / \sqrt{(s)}$ for the boundaries between the dry zone and evaporation zone, the evaporation zone and condensation zone, and the condensation zone and external zone, respectively. With an increasing number of dryingremoistening cycles, the propagation constants of the zone boundaries did not significantly change (Fig. 7). Sands pretreated at $225{ }^{\circ} \mathrm{C}$ or $330{ }^{\circ} \mathrm{C}$ also did not show relevant differences (Fig. 8). After a pre-treatment at $390{ }^{\circ} \mathrm{C}$, however, the propagation constant of the boundary between the condensation zone and external zone increased to $3.9 \pm 0.1 \mathrm{~mm} / \sqrt{(s)}$. Upon increasing the temperature of the heat pre-treatment to $750{ }^{\circ} \mathrm{C}$, the propagation of the boundary of the condensation zone and external zone increased to $6.4 \mathrm{~mm} / \sqrt{(s)}$ (single measurement). In comparison to the propagation of the boundary of the condensation zone and external zone, the effect of pre-treatment on the propagation of the other two boundaries was less prominent.

The maximum water contents measured at the boundary between evaporation zone and condensation zone remained at $5 \pm 0.5 \mathrm{wt} \%$, independent of cyclic reuse or of heat pretreatment (Fig. 9).

\subsection{Water in smectite interlayers at temperatures up to $130{ }^{\circ} \mathrm{C}$}

\subsubsection{Reference sand}

The 001-reflection of smectite was measured in all sands while applying a defined heating protocol. Before heating, the $d_{001}$-value of the smectite in the reference sample was $17.1 \AA$ (Fig. 10a). With increasing temperature, the $d$ value decreased reflecting a release of interlayer water. The water release rate, however, was not constant. Heating to $100{ }^{\circ} \mathrm{C}$ and keeping the temperature for about $1 \mathrm{~h}$ caused only a slight decrease of the $d_{001}$ value to $15.9 \AA$. Heating and 


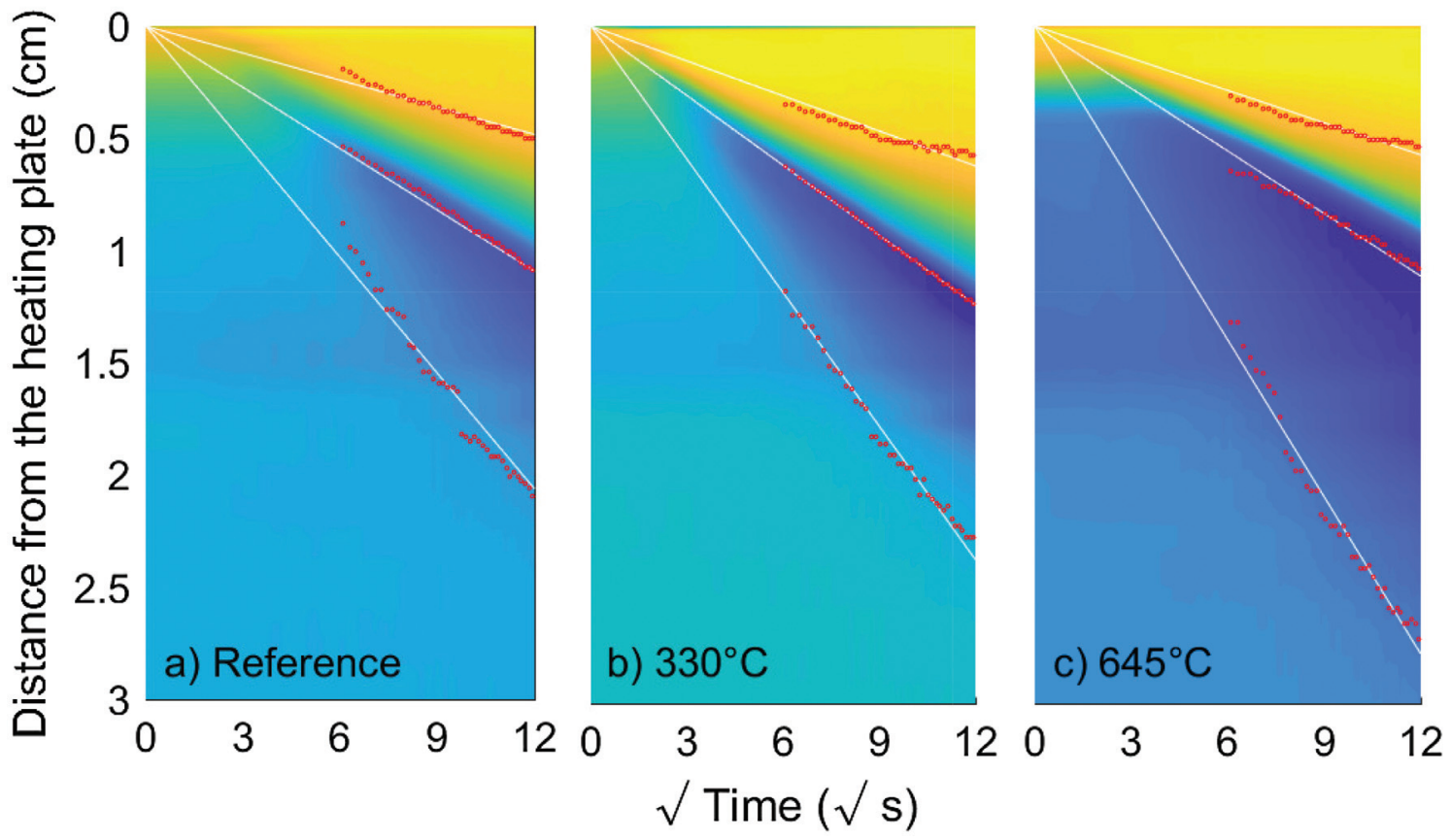

Fig. 6. Heat-driven movement of the water within the centre of the sample tube (same colour code as in Fig. 2) depicted by plotting a square root of time sequence of vertical profiles of neutron radiographs. (a) Reference sand; (b) sand pre-treated at $330{ }^{\circ} \mathrm{C}$; (c) sand pre-treated at $645{ }^{\circ} \mathrm{C}$. The red dots mark the measured boundaries between (from top to bottom) the dry zone, evaporation zone, condensation zone, and the external zone. The white lines are the linear regressions of the measured data points.

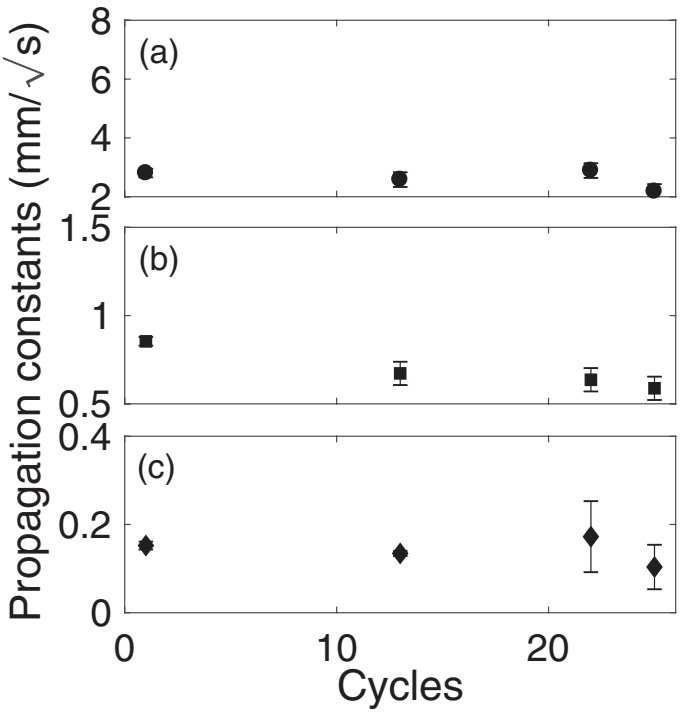

Fig. 7. Propagation constants of the zone boundaries calculated from neutron radiographs of cyclically reused sands plotted versus the number of cycles. (a) Boundary of condensation and external zone; (b) boundary of evaporation zone and condensation zone; (c) boundary of dry zone and evaporation zone.

keeping the sand at $110{ }^{\circ} \mathrm{C}$ for almost one hour led to an almost continuous decrease of the $d$ value to $13.1 \AA$. Heating to $120^{\circ} \mathrm{C}$ and keeping the temperature for another hour caused a further decrease of the $d$ value. Upon reaching $130{ }^{\circ} \mathrm{C}$, the 001-refection disappeared in the background with a final $d$ value of approximately $9.7 \AA$.

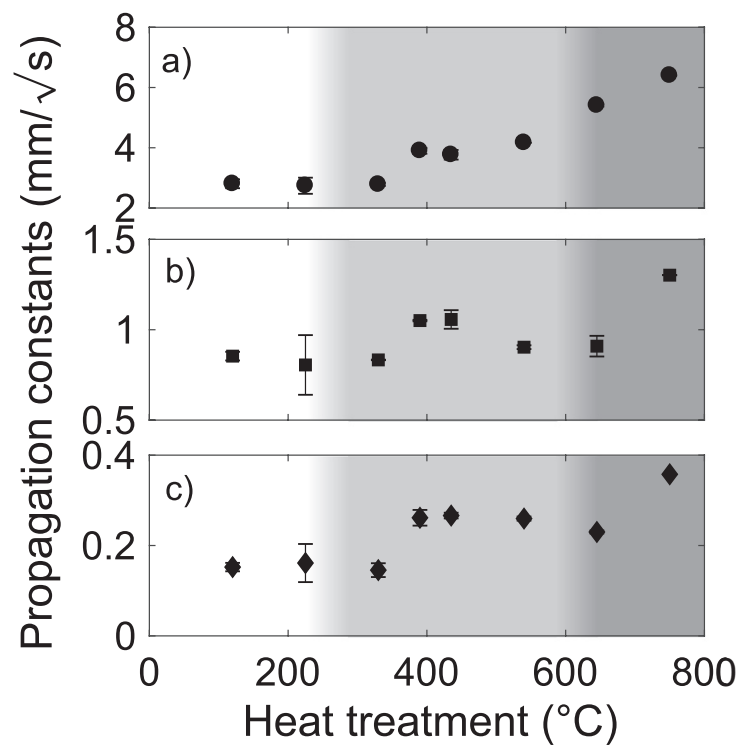

Fig. 8. Propagation constants of the zone boundaries calculated from neutron radiographs of heat pre-treated moulding sands plotted versus pre-treatment temperature. (a) Boundary of condensation zone and external zone; (b) boundary of evaporation zone and condensation zone; (c) boundary of dry zone and evaporation zone. Different degrees of weight loss during heat pre-treatment as detected by thermal analyses (Fig. 3) were indicated by different greyscales.

\subsubsection{Cyclically reused sands}

The temperature dependence of $d_{001}$ values of cyclically reused sands revealed some differences (Fig. 10b). During heating to $100{ }^{\circ} \mathrm{C}$, the $d_{001}$ value was approx. $19.6 \AA$. Upon 


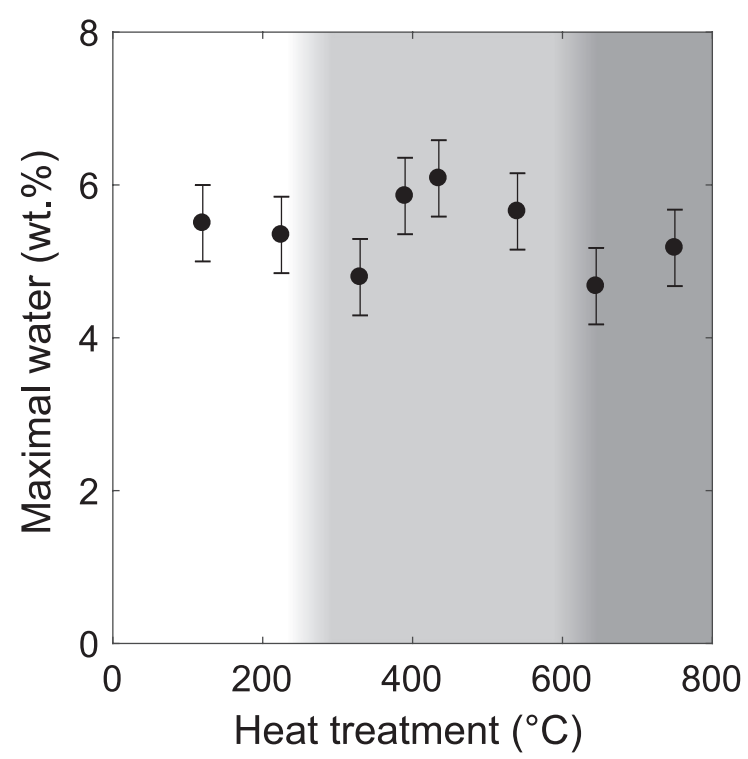

Fig. 9. Maximum water content at the boundary between evaporation zone and condensation zone for heat pre-treated sands during wet tensile strength testing. Different degrees of weight loss during heat pre-treatment as detected by thermal analyses (Fig. 3) were indicated by different greyscales.

heating to $110^{\circ} \mathrm{C}$, the $d$ value decreased to approx. $14.9 \AA$, stayed for some period, then decreased to approx. 13.7 $\AA$. Even after heating to $120{ }^{\circ} \mathrm{C}$, the $d$ value remained at approx. $13.7 \AA$ for some time before it dropped and stayed at $12.5 \AA$. Upon heating to $130{ }^{\circ} \mathrm{C}$, the 001-reflection disappeared in the background with a final $d$ value of approx. $10.5 \AA$. In summary, cyclically reused sands showed significantly higher initial and final $d$ values (19.6 and $10.5 \AA$ ).

\subsubsection{Heat pre-treated sands}

Sands pre-treated at $T \leq 435{ }^{\circ} \mathrm{C}$ (Fig. 10c) showed a very large initial $d$ value of approx. $20 \AA$. The spacing then decreased to approx. 15.7 $\AA$ where it remained until the temperature reached $115^{\circ} \mathrm{C}$. At $115^{\circ} \mathrm{C}$, the $d$ value then dropped to $13 \AA$. Upon heating to $120^{\circ} \mathrm{C}$, a further plateau was obtained at $12 \AA$. The reflection finally disappeared in the background with a $d$ value of approx. 9.6 $\AA$. In summary, a pre-treatment at $T \leq 435{ }^{\circ} \mathrm{C}$ led to an initial $d$ value, which was significantly higher than the one of the reference smectite. The final $d$ value was similar to the one of the reference.

\subsubsection{Amount of interlayer water}

The $d$ value of the smectites allowed a rough estimation of the amount of water, which is present within the smectite interlayers. Taking the results of Teich-McGoldrick et al. (2015), a $d_{001}$ value of $16 \AA(18 \AA)$ corresponded to approximately $5(6.5)$ molecules of water per $\mathrm{O}_{10}(\mathrm{OH})_{2}$. Approximating the molar weight of the dry smectite with $370 \mathrm{~g} / \mathrm{mol}$ per formula unit, $1 \mathrm{~g}$ of dry smectite

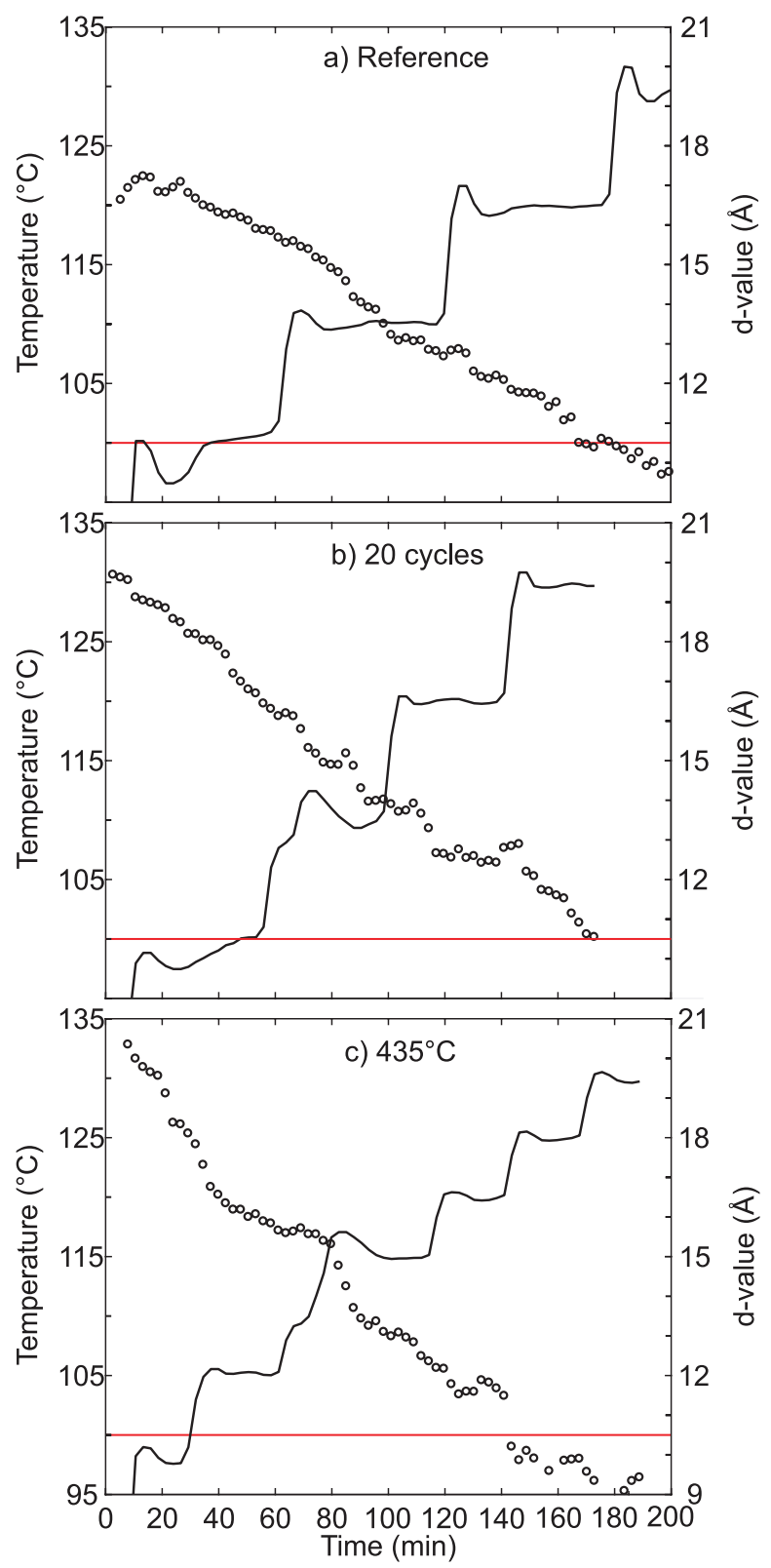

Fig. 10. Neutron diffractometer analyses conducted during thermal dehydration of the reference sand (a), cyclically reused sand (b), and sand pre-treated at $435{ }^{\circ} \mathrm{C}$ (c). The $d_{001}$ value of smectite (empty circles) and sample temperature (black line) are plotted versus time. The red lines mark the $100{ }^{\circ} \mathrm{C}$ levels and illustrate the periods of the sample temperature exceeding $100{ }^{\circ} \mathrm{C}$.

absorbed approx. $0.25 \mathrm{~g}(0.31 \mathrm{~g})$ in order to attain a layer-to-layer distance of $16 \AA$ (18 $\AA$ ). The moulding sand with a bentonite content of $8 \mathrm{wt} \%$, therefore, contained $1.7(2.2) \mathrm{wt} \%$ of water within the smectite interlayers at these swelling states.

\subsection{Sand structure}

The SEM images (Fig. 11) of the reference sand showed that the quartz grains were covered with smectite completely. 

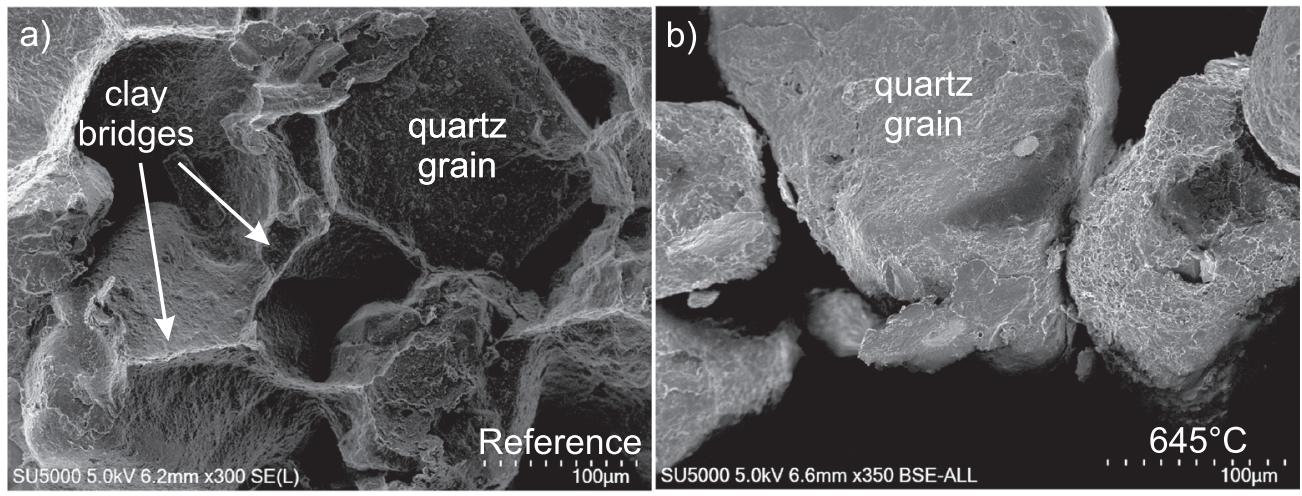

Fig. 11. SEM images of air-dried sand. (a) Reference sand; (b) sand pre-treated at $645{ }^{\circ} \mathrm{C}$.

The covering film interconnected neighbouring quartz grains and, thus, built up a three-dimensional framework in which the quartz grains were embedded. Contrarily, sands pre-treated with temperatures of $645{ }^{\circ} \mathrm{C}$ lacked the interconnecting three-dimensional framework and were composed of only partially connected quartz grains.

\section{Discussion}

\subsection{Effects of temperature and water kinematics on tensile strength}

In unheated moist moulding sand, capillary force controls tensile strength (Munkholm \& Kay, 2002; Heibrock et al., 2005; Forsmo et al., 2006; Zeh \& Witt, 2007; Vanicek, 2013). The capillary force is mainly depending on surface tension and can be assessed by sand suction ( $\mathrm{Lu}$ et al., 2007). Furthermore, capillary force depends on the swelling state of the smectites, which in unheated sand affects the amount of water in the pore space. All in all, tensile strength, therefore, is affected by the strength of water sorption forces, the water-air interface energy within the pores (Kayser, 1976; Wiebe et al., 1998), the relative pore humidity, and the pore structure, which changes with the swelling state of smectites (Wiebe et al., 1998).

In heated wet tensile testing as well as during casting, moulding sand develops a non-uniform temperature and moisture gradient (Kubo \& Pehlke, 1986). A zone with low tensile strength, therefore, forms which becomes manifested by the rupture position in tensile tests. In all experiments except the ones with sands pre-heated at $T>645{ }^{\circ} \mathrm{C}$, rupture occurred at the $100^{\circ} \mathrm{C}$ isotherm (Fig. 2). This isotherm corresponded to the boundary between evaporation zone and condensation zone (Kubo \& Pehlke, 1986), where the pore water began to evaporate and the relative pore humidity was $100 \%$. This pore water evaporation and the concomitant decrease in capillary force, therefore, can be regarded as the major causes for the decrease in tensile strength at this boundary. The retaining minimum tensile strength mainly depended on the stability of the clay mineral bridges (Fig. 11), which is related to the swelling state of the smectites (Laird, 2006).
Although the location of weakest strength in the sand column correlated with the $100{ }^{\circ} \mathrm{C}$ isotherm, the tensile strength at this weakest location was not always the same. The temperature dependence of the tensile strength, therefore, cannot explain the observed differences among the sands. The integrity of the smectite structure and composition has to be taken into account as well. The intactness of smectites may play a role by affecting the water contents of the different sands. In the sand, water resided in three different reservoirs: pores, surfaces, smectite interlayers. In order to understand the different tensile strengths of the sands, knowledge of the amounts of water within the respective reservoirs is important. These amounts were influenced by the heat-driven water kinematics within the sand column, and, on a smaller scale, by the retention capacity of the smectite interlayers or, from a more general perspective, by the water kinematics between the three reservoirs.

The comparision of the diffusion constant of water molecules in and out of the smectite interlayers $\left(\approx 9 \times 10^{-9} \mathrm{~m}^{2} /\right.$ s; Bourg \& Sposito, 2010; Holmboe \& Bourg, 2014) with the propagation constant of the boundary between the evaporation zone and condensation zone $\left(\approx 8 \times 10^{-7} \mathrm{~m}^{2} / \mathrm{s}\right.$; Figs. 7,8 ) shows that hydration and dehydration of the smectite interlayers is orders of magnitudes slower than the heat driven movement of water within the pore system of the moulding sand. This is confirmed by neutron diffraction, which showed that certain hydration states were stable for much longer time scales (Fig. 10) than relevant for moulding sand stability, both in wet tensile testing and in foundry industry. Therefore, absorption capacity of the smectite interlayers played an inferior role in buffering the rising supersaturation at the advancing condensation zone.

The maximum water content at the boundary between evaporation zone an condensation zone was predominantly controlled by the heat capacity of the moulding sand (Kubo \& Pehlke, 1986). Because smectite alteration did not strongly influence the specific heat of the sand, the maximum water contents of the different sands did not differ significantly (Fig. 9).

At the boundary between evaporation zone and condensation zone, therefore, not only the temperature and porosity but also the total water content was independent of the sand 
pre-treatment. Thus, the stability of the clay mineral bridges likely was the main factor determining the minimum tensile strength at the rupture plane.

\subsection{Tensile strength of cyclically reused sands}

Comparing the propagation constants and the tensile strengths of the reference sand and the cyclically reused sands, no significant changes with an increasing number of drying and remoistening cycle could be observed (Fig. 7).

The neutron diffraction data at $100{ }^{\circ} \mathrm{C}$ showed that the $d_{001}$ value of smectites in the reference sand as well as in the cyclically reused sands roughly corresponded to three water layers (Zheng et al., 2010; Villar et al., 2012; Holmboe \& Bourg, 2014). The amount of water within these smectite interlayer was approximately between 1.7 and $2.2 \mathrm{wt} \%$. Thus, about the half of the total water at the boundary between evaporation zone and condensation zone (approx. $5 \mathrm{wt} \%$; Fig. 9) was located within the smectite interlayers.

Note, the $d$ values of the smectites in the cyclically reused sands were approx. $1.5 \AA$ larger than in the reference sand (Fig. 10). In agreement with Heuser et al. (2014), we suggest that these higher initial $d$ values were likely caused by mechanical effects originating from repeated mixing (Oscarson et al., 1990; Alonso-Santurde et al., 2012) rather than by steam (Couture, 1985; Oscarson \& Dixon, 1989). If steam were the cause, smectite in the reference sand would show a high $d$ value, too, because a single steam treatment would likely be effective enough to expand the layers.

\subsection{Tensile strength of sands pre-treated at $T=225-330{ }^{\circ} \mathrm{C}$}

The effect of heat pre-treatment was investigated by a separate suite of experiments. Neutron radiography experiments with sand pre-treated at temperatures up to $330{ }^{\circ} \mathrm{C}$ revealed no significant alteration of the propagation constants (Fig. 8). However, neutron diffraction analyses during dehydration of these pre-treated sands showed (Fig. 10) that the initial smectite $d_{001}$ values at temperatures up to $100{ }^{\circ} \mathrm{C}$ were significantly larger than in the reference sand. A mechanical cause for these increased initial $d$ values (as in the case of cyclically reused sands) can be dismissed because the mechanical treatment was as long and strong as in the reference sand. Thus, the heat pre-treatment at $T=225-330{ }^{\circ} \mathrm{C}$ has to be the reason for these increased $d$ values. In agreement with the results obtained by thermal analysis, the pretreatment may only have led to minor changes of the smectite structure if any. In the case of small interlayer cations such as $\mathrm{Li}, \mathrm{Cu}, \mathrm{Zn}$, migration into tetrahedral sheets (McBride \& Mortland, 1974) or octahedral sites (Madejová et al., 1996) might be considered as an adequate structural modification. Larger cations $(\mathrm{Na}, \mathrm{Ca})$ migrate into these sites less likely (Calvet \& Prost, 1971). However, also for smectites with larger cations like $\mathrm{Na}^{+}, \mathrm{K}^{+}, \mathrm{Ca}^{2+}$ small changes in properties upon heating temperature were reported in literature (Chorom \& Rengasamy, 1996; Komadel et al., 2005).
We propose that irreversible minor structural changes induced by the heat pre-treatment were apt to reduce the forces between the smectites bridging two quartz grains (Laird, 2006) and, therefore, were responsible for the decrease in wet tensile strength, which was obtained for sands pre-treated at temperatures of $225-330{ }^{\circ} \mathrm{C}$.

\subsection{Tensile strength of sands pre-treated at $\boldsymbol{T}>330{ }^{\circ} \mathrm{C}$}

Pre-treatments of sands at $T>330{ }^{\circ} \mathrm{C}$ led to changes in water kinematics that were more substantial. All three propagation constants were increased in sands pre-treated at temperatures between 390 and $540{ }^{\circ} \mathrm{C}$ (Fig. 8; range marked in pale greyscale). The increase of propagation constants correlated with the observed mass loss by TG and the endothermic DSC-peak reaching maximum at $500{ }^{\circ} \mathrm{C}$ (Fig. 3). These thermal analyses very likely reflect a loss of tightly bound water (Kuligiewicz \& Derkowski, 2017) or an early loss of hydroxyl-groups (Emmerich et al., 1999), although for cis-vacant montmorillonites dehydroxylation was found to take place not below $600{ }^{\circ} \mathrm{C}$ (Wolters \& Emmerich, 2007). Irrespective of the removal of tightly bound water or hydroxyl-groups, the changes of smectites by the heat pre-treatment were the likely cause of the observed tensile strength reduction.

It needs to be noted, however, that the smectites located at the rupture plane (i.e., at $100{ }^{\circ} \mathrm{C}$ isotherm of the sample column) still contained three layers of water. This high amount of interlayer water was likely facilitated by the high partial pressure of water in the pore space of the sand ( $c f$. Emmerich et al., 2015). This interlayer water is indicative of the existence of some layer charge and is a clear indication for only minor or moderate changes of the smectites at temperatures below $645^{\circ} \mathrm{C}$.

Pre-treatments at $T \geq 645{ }^{\circ} \mathrm{C}$ caused a strong increase of the propagation constant of the boundary between the condensation zone and external zone (Fig. 8; range marked in dark greyscale). Pre-treatments at $750{ }^{\circ} \mathrm{C}$, led to significantly higher values of all propagation constants. The increased water transport rates and decreased tensile strengths correlated with the observed DSC-peak at $670{ }^{\circ} \mathrm{C}$ (Fig. 3), which is typically for a dehydroxylation of cis-vacant montmorillonite (Emmerich et al., 2009).

SEM of these samples showed quartz grains being located individually rather than interconnected by smectite coatings (Fig. 11b). The most prominent property change, however, was that sand pre-treated at $T \geq 645{ }^{\circ} \mathrm{C}$ did not harden in dry state but transformed into loose grains. The tensile strengths of these sands, therefore, decreased to zero in all areas where the water bridges between the grains were evaporated completely. Consequently, the position of the rupture plane of these sands shifted into the dry zone.

\section{Conclusion}

Although there were small differences in the $d_{001}$ values of smectites between the reference sand and sands subjected to 
22 drying and remoistening cycles, significant changes in water kinematics and tensile strength could not be detected. Thus, the observed effects caused by the cyclic reuse were not yet strong enough to affect the attractive forces in a magnitude leading to a substantial reduction of the quality of the moulding sand. This finding agrees with empiric practice in foundry industry, where moulding sand is replaced after approx. 20 cycles. The fact that slight alterations were detected, however, may indicate that a higher number of cycles eventually will lead to a decrease of sand quality. In this context, it needs to be noted that in our experiments the maximum temperature during cyclic reuse was $120^{\circ} \mathrm{C}$. A high-temperature impact, as it typically occurs during casting, was not part of these cycles.

The influences of heat pre-treatment on the water transport and binding properties of moulding sands were investigated for the first time. Alterations were detected already at $T=225{ }^{\circ} \mathrm{C}$, i.e. at a temperature, which supposedly is well below the dehydroxylation threshold of smectites. The alterations mainly comprised of an increased water transport rate in the moulding sand column. We suggest that this modified water kinematics is a consequence of minor changes of the compositional and structural integrity of the smectites and is causally related to the observed degradation of the mechanical properties of the moulding sands. Upon an early dehydroxylation of the the smectites or a progressive release of tightly bound water at $T>330{ }^{\circ} \mathrm{C}$, further irreversible decrease of the binding quality of moulding sands occurred. With completing dehydroxylation of the smectites above $670{ }^{\circ} \mathrm{C}$, the total loss of wet tensile strength of the preheated sands took place.

Acknowledgements: The work is based on experiments performed at ANTARES and MIRA operated by Heinz Maier-Leibnitz Zentrum (MLZ, Garching Germany) as well as at ICON (Paul-Scherrer-Institute, Villigen, Switzerland). Funding from DFG (JO301/5-1) is gratefully acknowledged. Furthermore, the authors would like to kindly thank Erika Grießhaber (LMU München) for SEM analyses. The helpful reviews of two anonymous reviewers and the associate editor are gratefully acknowledged.

\section{References}

Alonso-Santurde, R., Coz, A., Viguri, J., Andrés, A. (2012): Recycling of foundry by products in the ceramic industry: Green and core sand in clay bricks. Constr. Build. Mater., 27(1), 97-106.

Berend, I., Cases, J.-M., Francois, M., Uriot, J.-P., Michot, L., Masion, A., Thomas, F. (1995): Mechanism of adsorption and desorption of water vapor by homoionic montmorillonites: 2 . The $\mathrm{Li}^{+}, \mathrm{Na}^{+}, \mathrm{K}^{+}, \mathrm{Rb}^{+}$and $\mathrm{Cs}^{+}$-exchanged forms. Clays Clay Minerals, 43, 324-336.

Bobrowski, A. \& Grabowska, B. (2012): The impact of temperature on furan resin and binders structure. Metall. Foundry Eng., 38, 73-80.

Bourg, I. C. \& Sposito, G. (2010): Connecting the molecular scale to the continuum scale for diffusion processes in smectite-rich porous media. Environ. Sci. Technol., 44(6), 2085-2091.
Calvet, R. \& Prost, R. (1971): Cation migration into empty octahedral sites and surface properties of clays. Clays Clay Minerals, 3, 175-186.

Cases, J., Bérend, I., Besson, G., Francois, M., Uriot, J., Thomas, F., Poirier, J. (1992): Mechanism of adsorption and desorption of water vapor by homoionic montmorillonite. 1. The sodiumexchanged form. Langmuir, 8(11), 2730-2739.

Chorom, M. \& Rengasamy, P. (1996): Effect of heating on swelling and dispersion of different cationic forms of a smectite. Clays Clay Minerals, 44(6), 783-790.

Couture, R. A. (1985): Steam rapidly reduces the swelling capacity of bentonite. Nature, 318(6041), 50-52.

Emmerich, K., Madsen, F. T., Kahr, G. (1999): Dehydroxylation behavior of heat treated and steam-treated homoionic cis-vacant montmorillonites. Clays Clay Minerals, 47(5), 591-604.

Emmerich, K., Wolters, F., Kahr, G., Lagaly, G. (2009): Clay profiling: the classification of montmorillonites. Clays Clay Minerals, 57(1), 104-114.

Emmerich, K., Koeniger, F., Kaden, H., Thissen, P. (2015): Microscopic structure and properties of discrete water layer in Na-exchanged montmorillonite. J. Coll. Interf. Sci., 448, 24-31.

Ferrage, E., Kirk, C. A., Cressey, G., Cuadros, J. (2007): Dehydration of $\mathrm{Ca}$ montmorillonite at the crystal scale. Part I: Structure evolution. Am. Mineral., 92(7), 994-1006.

Fiore, S. \& Zanetti, M. C. (2007): Foundry wastes reuse and recycling in concrete production. Am. J. Environ. Sci., 3(3), 135-142.

Forsmo, S., Apelqvist, A., Björkman, B., Samskog, P.-O. (2006): Binding mechanisms in wet iron ore green pellets with a bentonite binder. Powder Technol., 169(3), 147-158.

Georgii, R. \& Seemann, K. (2015): Mira: Dual wavelength band instrument. JLSRF, 1, 3.

Georgii, R., Weber, T., Brandl, G., Skoulatos, M., Janoschek, M., Mühlbauer, S., Pfleiderer, C., Böni, P. (2018): The multipurpose three-axis spectrometer (TAS) MIRA at FRM II. Nucl. Instrum. Methods Phys. Res. A, 881, 60-64.

Grefhorst, C. (2006): Prüfung von Bentoniten: Ausführliche Bewertung der Eigenschaften und ihr Wert für die Praxis. Giesserei, 93(5), 26-31.

Guney, Y., Sari, Y. D., Yalcin, M., Tuncan, A., Donmez, S. (2010): Re-usage of waste foundry sand in high-strength concrete. Waste Manag., 30(8), 1705-1713.

Hall, S. A. (2013): Characterization of fluid flow in a shear band in porous rock using neutron radiography. Geophys. Res. Lett., 40(11), 2613-2618.

Hassanein, R., Meyer, H. O., Carminati, A., Estermann, M., Lehmann, E., Vontobel, P. (2006): Investigation of water imbibition in porous stone by thermal neutron radiography. $J$. Phys. D: Appl. Phys., 39, 4284-4291.

Heibrock, G., Zeh, R. M., Witt, K. J. (2005): Tensile strength of compacted clays. in "Unsaturated soils: Experimental studies", Schanz, T. ed., Springer, Berlin, 395-412.

Heuser, M., Weber, C., Stanjek, H., Chen, H., Jordan, G., Schmahl, W. W., Natzeck, C. (2014): The interaction between bentonite and water vapor. I: examination of physical and chemical properties. Clays Clay Minerals, 62(3), 188-202.

Holmboe, M. \& Bourg, I. C. (2014): Molecular dynamics simulations of water and sodium diffusion in smectite interlayer nanopores as a function of pore size and temperature. J. Phys. Chem. C, 118(2), 1001-1013.

Holtzer, M., Bobrowski, A., Zymankowska-Kumon, S. (2011): Temperature influence on structural changes of foundry bentonites. J. Mol. Struct., 1004(1), 102-108.

Jordan, G., Eulenkamp, C., Calzada, E., Schillinger, B., Hoelzel, M., Gigler, A., Stanjek, H., Schmahl, W. W. (2013): Quantitative insitu study of the dehydration of bentonite-bounded moulding sands. Clays Clay Minerals, 61(2), 133-144. 
Kaestner, A., Hartmann, S., Kühne, G., Frei, G., Grünzweig, C., Josic, L., Schmid, F., Lehmann, E. (2011): The ICON beamline - a facility for cold neutron imaging at SINQ. Nucl. Instrum. Methods Phys. Res. A, 659(11), 387-393.

Kayser, W. V. (1976): Temperature dependence of the surface tension of water in contact with its saturated vapor. J. Coll. Interf. Sci., 56(3), 622-627.

Keren, R. \& Shainberg, I. (1975): Water vapor isotherms and heat of immersion of $\mathrm{Na} / \mathrm{Ca}$-montmorillonite systems: I. Homoionic clay. Clays Clay Minerals, 23(3), 193-200.

_ - (1979): Water vapor isotherms and heat of immersion of $\mathrm{Na} / \mathrm{Ca}$-montmorillonite systems: II. Mixed systems. Clays Clay Minerals, 27(2), 145-151.

Komadel, P., Madejová, J., Bujdák, J. (2005): Preparation and properties of reduced charge smectites - a review. Clays Clay Minerals, 53(4), 313-334.

Kubo, K. \& Pehlke, R. D. (1986): Heat and moisture transfer in sand molds containing water. Metall. Trans. B, 17(4), 903-911.

Kuligiewicz, A. \& Derkowski, A. (2017): Tightly bound water in smectites. Am. Mineral., 102(5), 1073-1090.

Laird, D. A. (2006): Influence of layer charge on swelling of smectites. Appl. Clay Sci., 34(1-4), 74-87.

Lu, N., Wu, B., Tan, C. P. (2007): Tensile strength characteristics of unsaturated sands. J. Geotech. Geoenviron. Eng., 133(2), 144-154.

Madejová, J., Bujdák, J., Komadel, P., Gates, W. (1996): Preparation and infrared spectroscopic characterization of reduced-charge montmorillonite with various Li contents. Clay Minerals, 31(2), 233-241.

McBride, M. \& Mortland, M. (1974): Copper (II) interactions with montmorillonite: evidence from physical methods. Soil Sci. Soc. Am. J., 38(3), 408-415.

Mooney, R., Keenan, A., Wood, L. (1952a): Adsorption of water vapor by montmorillonite. I. Heat of desorption and application of BET theory. J. Am. Chem. Soc., 74(6), 1367-1371.

$-, \ldots,-(1952 \mathrm{~b})$ : Adsorption of water vapor by montmorillonite. II. Effect of exchangeable ions and lattice swelling as measured by X-ray diffraction. J. Am. Chem. Soc., 74(6), 1371-1374.

Munkholm, L. J. \& Kay, B. D. (2002): Effect of water regime on aggregate-tensile strength, rupture energy, and friability. Soil Sci. Soc. Am. J., 66, 702-709.

Ogata, K., Takeuchi, Y., Kudoh, Y. (1987): Structure of quartz as a function of temperature and pressure. Z. Kristallog. Cryst. Mater., 179(1-4), 403-414.

Oscarson, D. \& Dixon, D. (1989): The effect of steam on montmorillonite. Appl. Clay Sci., 4(3), 279-292.

Oscarson, D., Dixon, D., Gray, M. (1990): Swelling capacity and permeability of an unprocessed and a processed bentonitic clay. Eng. Geol., 28(3-4), 281-289.

Patterson, W. \& Boenisch, D. (1961): Die Bedeutung der Festigkeit feuchter, tongebundener Formsande insbesondere der Naßfestigkeit. Giesserei, 3, 157-193.

_, (1964): Das Schülpendiagramm für Naßzugsande. Giesserei, 51(21), 634-641.

Raupp-Pereira, F., Hotza, D., Segadães, A., Labrincha, J. (2006): Ceramic formulations prepared with industrial wastes and natural sub-products. Ceram. Int., 32(2), 173-179.

Schiebel, K., Jordan, G., Kaestner, A., Schillinger, B., Boehnke, S., Schmahl, W. W. (2018): Neutron radiographic study of the effect of heat-driven water transport on the tensile strength of bentonite-bonded moulding sand. Transp. Porous Media, 121(2), 369-387.

Schillinger, B., Calzada, E., Eulenkamp, C., Jordan, G., Schmahl, W. W. (2011): Dehydration of moulding sand in simulated casting process examined with neutron radiography. Nucl. Instrum. Methods Phys. Res. A, 651(1), 312-314.
Schnetzer, F., Thissen, P., Giraudo, N., Emmerich, K. (2016): Unraveling the coupled processes of (de) hydration and structural changes in $\mathrm{Na}^{+}$-saturated montmorillonite. J. Phys. Chem. C, 120(28), 15282-15287.

Schulz, M. \& Schillinger, B. (2015): Antares: Cold neutron radiography and tomography facility. $J L S R F, 1$ (A17), 1-4.

Sedighi-Gilani, M., Wakili, K. G., Koebel, M., Hugi, E., Carl, S., Lehmann, E. (2013): Visualizing moisture release and migration in gypsum plaster board during and beyond dehydration by neutron radiography. Int. J. Heat Mass Transfer, 60, 248-290.

Siddique, R., De Schutter, G., Noumowe, A. (2009): Effect of usedfoundry sand on the mechanical properties of concrete. Constr. Build. Mater, 23(2), 976-980.

Teich-McGoldrick, S. L., Greathouse, J. A., Jove-Colon, C. F., Cygan, R. T. (2015): Swelling properties of montmorillonite and beidellite clay minerals from molecular simulation: comparison of temperature, interlayer cation, and charge location effects. $J$. Phys. Chem. C, 119(36), 20880-20891.

Tilch, W., Grefhorst, C., Kleimann, W. (2002): Fachaufsätze Bentonite als Formstoffbinder - eine praxisnahe Bewertung der Eigenschaften - Anforderungen an bentonitgebundene Formstoffe - Bentonite - Fertigungsprozess - Aufbereitungsverhalten. Gießerei Praxis, 2, 53-62.

Vanicek, I. (2013): The importance of tensile strength in geotechnical engineering. Acta Geot. Slov., 1, 5-9.

Villar, M., Gómez-Espina, R., Gutiérrez-Nebot, L. (2012): Basal spacings of smectite in compacted bentonite. Appl. Clay Sci., 65, 95-105.

Wang, Y., Cannon, F. S., Salama, M., Goudzwaard, J., Furness, J. C. (2007a): Characterization of hydrocarbon emissions from green sand foundry core binders by analytical pyrolysis. Environ. Sci. Technol., 41(22), 7922-7927.

Wang, Y., Huang, H., Cannon, F. S., Voigt, R. C., Komarneni, S., Furness, J. C. (2007b): Evaluation of volatile hydrocarbon emission characteristics of carbonaceous additives in green sand foundries. Environ. Sci. Technol., 41(8), 2957-2963.

Wersin, P., Johnson, L., McKinley, I. (2007): Performance of the bentonite barrier at temperatures beyond $100{ }^{\circ} \mathrm{C}$ : A critical review. Phys. Chem. Earth, 32(8), 780-788.

Wiebe, B., Graham, J., Tang, G. X., Dixon, D. (1998): Influence of pressure, saturation, and temperature on the behaviour of unsaturated sand-bentonite. Can. Geotech. J., 35(2), 194-205.

Wolters, F. \& Emmerich, K. (2007): Thermal reactions of smectites - relation of dehydroxylation temperature to octahedral structure. Thermochim. Acta, 462(1-2), 80-88.

Zabat, M. \& Van Damme, H. (2000): Evaluation of the energy barrier for dehydration of homoionic ( $\mathrm{Li}, \mathrm{Na}, \mathrm{Cs}, \mathrm{Mg}, \mathrm{Ca}, \mathrm{Ba}$, $\mathrm{Al}_{\mathrm{x}}(\mathrm{OH})_{\mathrm{y}} 633^{\mathrm{z}+}$ and La)-montmorillonite by a differentiation method. Clay Minerals, 35(2), 357-363.

Zanetti, M. \& Godio, A. (2006): Recovery of foundry sands and iron fractions from an industrial waste landfill. Resour. Conserv. Recycl., 48(4), 396-411.

Zeh, R. M., \& Witt, K. J. (2007): The tensile strength of compacted clays as affected by suction and soil structure. in "Experimental unsaturated soil mechanics", Zeh, R. M., \& Schanz, T. ed., Springer, Berlin, Heidelberg, 219-226.

Zheng, Y., Zaoui, A., Shahrour, I. (2010): Evolution of the interlayer space of hydrated montmorillonite as a function of temperature. Am. Mineral., 95(10), 1493-1499.

Zymankowska-Kumon, S., Holtzer, M., Olejnik, E., Bobrowski, A. (2012): Influence of the changes of the structure of foundry bentonites on their binding properties. Mater. Sci., 18(1), 57-61.

Received 24 January 2018

Modified version received 30 April 2018

Accepted 6 June 2018 